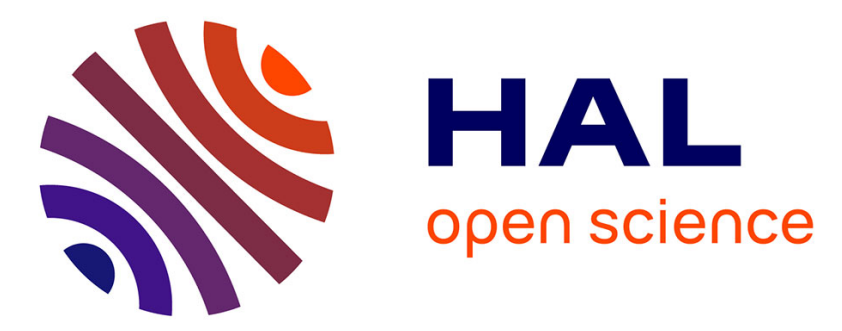

\title{
Extreme Wave Events on Barrier Reefs: A Driver for Critical Regime?
}

Damien Sous, Marion Tissier, Frédéric Bouchette, Guillaume Dodet, Vincent Rey

\section{- To cite this version:}

Damien Sous, Marion Tissier, Frédéric Bouchette, Guillaume Dodet, Vincent Rey. Extreme Wave Events on Barrier Reefs: A Driver for Critical Regime?. Journal of Coastal Research, 2020, 95 (sp1), pp.654-658. 10.2112/SI95-127.1 . hal-02899297

\section{HAL Id: hal-02899297 https://hal.science/hal-02899297}

Submitted on 2 Mar 2021

HAL is a multi-disciplinary open access archive for the deposit and dissemination of scientific research documents, whether they are published or not. The documents may come from teaching and research institutions in France or abroad, or from public or private research centers.
L'archive ouverte pluridisciplinaire HAL, est destinée au dépôt et à la diffusion de documents scientifiques de niveau recherche, publiés ou non, émanant des établissements d'enseignement et de recherche français ou étrangers, des laboratoires publics ou privés. 


\title{
Extreme Wave Events on Barrier Reefs: A Driver for Critical Regime?
}

\author{
Damien Sous $^{\dagger \dagger}$, Marion Tissier ${ }^{\S}$, Frédéric Bouchette ${ }^{\dagger \dagger}$, Guillaume Dodet ${ }^{+*}$, and Vincent Rey ${ }^{\dagger}$ \\ 'Université de Tou- \\ lon, Aix Marseille \\ Université, CNRS, \\ IRD, Mediterranean \\ Institute of Ocean- \\ ography \\ La Garde, France \\ \#Univ Pau \& Pays \\ Adour/E2S UPPA, \\ Chaire HPC-Waves, \\ SIAME, \\ EA4581 Anglet, \\ France

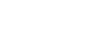 \\ ${ }^{\dagger}$ GEOSCIENC- \\ ES-Montpellier, \\ Univ Montpellier, \\ CNRS \\ Montpellier, France \\ HIFREMER, Univ. \\ Brest, CNRS, IRD, \\ Laboratoire d'Océa- \\ nographie Physique \\ et Spatiale (LOPS), \\ IUEM \\ Brest, France \\ Delft, The Nether- \\ lands \\ Fluid Mechanics \\ Section, Faculty of \\ and Geosciences, \\ Delft University of \\ Technology
}

ABSTRACT

\begin{abstract}
This paper describes the hydrodynamic regimes reached over barrier reefs during extreme wave events. The study is based on a combined approach relying, on one hand, on an extensive in-situ experiment over the Ouano reef-lagoon system, New Caledonia and, on the other hand, on wave-resolving numerical modeling.
\end{abstract}

ADDITIONAL INDEX WORDS: Barrier reefs, extreme waves, wave-induced setup, Froude number, pressure gradient.

\section{INTRODUCTION}

Coral barrier reefs are found in many tropical islands. They provide an efficient protection from offshore wave energy, allowing the development of sheltered lagoon systems which are of primary importance for fish resources, navigational and recreational purposes. The water quality within the lagoon and the related health of ecosystems is strongly dependent on the circulation and renewal time of water masses. The exchanges fluxes with the ocean, combining mass, heat, nutrients and contaminants fluxes, are therefore directly related to the hydrodynamics of the reef barrier, in terms of currents, water level and wave activity (Chevalier et al., 2015, Sous et al., 2017, 2019a, b).

In usual wave conditions, the hydrodynamics above reef barriers is well described by the depth-averaged momentum balance (Hench, Leichter, and Monismith, 2008; Lentz et al., 2016, 2017; Lowe et al., 2005, 2009; Monismith et al., 2013; Sous et al., 2019). The basic mechanism is that wave breaking over the foreslope of barrier reefs induces a barotropic cross-shore component of current resulting from the balance between the gradient of radiation stress, the bottom friction, and the horizontal surface (setup) gradients.

The recent study of Sous et al. (2019b) provides a detailed characterization of the dynamics of each of the momentum terms involved in the cross-reef momentum balance, over a wide range of conditions. A very peculiar behavior has been observed during the strongest recorded wave event over the two-months survey period. The hypothesis put forward by the authors is that, during extreme wave forcing and particular depth conditions, the current induced by the cross-reef barotropic pressure gradient is so intense that a transition toward critical hydraulic regime is reached. If present, such mechanism should have strong consequence on the overall hydrodynamics across the barrier, including friction, mixing, wave propagation and water flux toward the lagoon. Such kind of critical transition has already been observed in reef platforms exposed to significant tidal forcing (Lowe et al., 2015), but the question remains if the waves alone are able to generate this shift toward critical hydraulic regime.

The aim of the present study is to focus the analysis on these peculiar conditions. The field database of Sous et al. (2019a, b) is thus re-analysed and compared with the predictions of a waveresolving numerical model.

\section{METHODS}

\section{Field Experiments}

The observational part of the present study relies on an in-situ data-set recovered from April to August, 2016. The studied site is the Ouano reef-lagoon system, South-West New Caledonia. It is an elongated coastal lagoon, nearly $30 \mathrm{~km}$ long, $10 \mathrm{~km}$ wide and $10 \mathrm{~m}$ deep. It has been classified as a channel lagoon (Sous et al., 2017). The reef-lagoon system is exposed to a micro-tidal regime (tidal range $1.7 \mathrm{~m}$ ) and south pacific swells. Further details on the lagoon functioning are reported elsewhere (Chevalier et al., 2015, Locatelli et al., 2017, Sous et al., 2017, 2019a, b).

The instrumentation is deployed on a single cross-reef transect (Figure 1). The forereef is the steepest and most rugged area, the reef flat is made of compact coral colonies with typical heighs of 


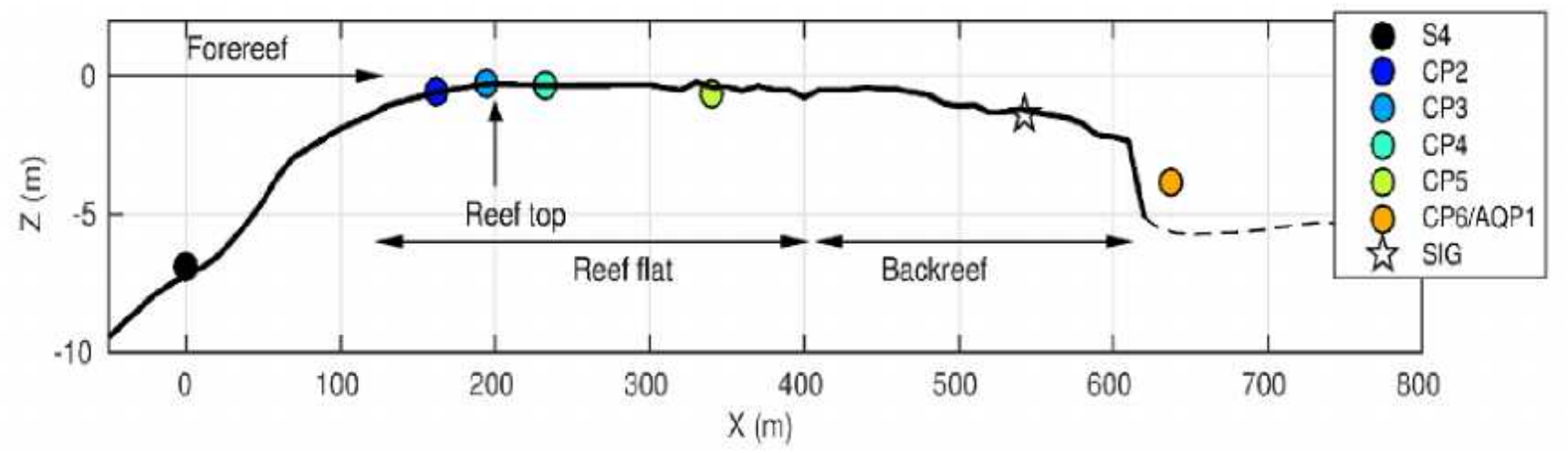

Figure 1. Instrumental setup along a cross-reef transect. Open ocean and lagoon are on the left and right boundaries, respectively. Black thick and dashed lines represent the area covered by coral reef and sand, respectively.

coral elements ranging between 0.1 and $0.4 \mathrm{~m}$ while the backreef is generally covered by smaller coral boulders $(0.1-0.2 \mathrm{~m})$ on a dead coral bed with scattered but larger pinnacles (up to 0.6-0.8 $\mathrm{m})$.

The instrumentation allows one to monitor both free surface waves and current. Incoming wave conditions are measured over the foreslope by a S4 electro-current meter, $7.3 \mathrm{~m}$ deep, with 20-min bursts recorded every $3 \mathrm{~h}$. Deep water wave height $H_{o}$ is obtained by reverse shoaling of the measured significant wave height using linear theory for shore normal waves. Wave data across the barrier are inferred from bottom pressure measurements performed by five autonomous sensors deployed from the reef top to the inner lagoon. The reef flat sensors CP2 to CP5 are OSSI Wave Gauge $(\mathbb{R}$ sensors recording continuously bottom pressure at $5 \mathrm{~Hz}$ while the lagoon pressure sensor CP6 is a RBR Duo sampling at $2 \mathrm{~Hz}$. Atmospheric pressure data from Tontouta airport is used to compensate the pressure measurements. Spectra of free surface elevations are computed over successive 40min burst using linear wave theory. Mean water levels (MWL) are computed by averaging the free surface elevation over 40 min bursts.

Current measurements are provided by two acoustic doppler velocity profilers. The first is a Nortek Signature 1000 (SIG) deployed above the backreef, measuring velocity during 20 min bursts at $4 \mathrm{~Hz}$. The second is a Nortek Aquadopp (AQP) measuring current profile at the entrance of the lagoon, just after the bathymetric step associated to the end of the barrier. Timeaveraged velocity profiles over $60 \mathrm{~s}$ bursts are computed each $20 \mathrm{~min}$. The measured velocities are projected into the reef main axis to obtain the cross and along-reef components. Positive values of cross-reef and along-reef components correspond to northward (water entering) and westward currents, respectively. An extensive comparison of cross-reef transports measured at SIG and AQP6 has been performed by Sous et al. (2019b), confirming the conservation of transport and the robustness of the cross-reef approach.

\section{Numerical Modeling}

The phase-resolving model SWASH is used with two vertical terrain-following layers. The domain is $2.5 \mathrm{~km}$ long $(-500<\mathrm{X}<2000$ $\mathrm{m})$ with $1 \mathrm{~m}$ of horizontal resolution. For $\mathrm{X}>-10 \mathrm{~m}$, the seafloor profile recovered from bathymetric surveys is used, while for deeper regions, a linear slope is assumed. At the offshore boundary, the model is forced by synthetic 20-min time series reconstructed from a Jonswap spectrum with inclusion of second-order bound infragravity waves. A $500 \mathrm{~m}$ wide sponge layer is finally imposed at the lagoon boundary. The model has been successfully tested and calibrated against wave height, setup and current data in Sous et al. $(2019 \mathrm{a}, \mathrm{b})$. All model parameters are kept to default values except for the depth-dependent Manning formulation used for the friction coefficient, with a spatially constant value. The Manning coefficient, which is fixed at $0.06 \mathrm{~s} . \mathrm{m}^{-1 / 3}$, has been calibrated on both wave height and mean water level.

\section{RESULTS}

\section{Field Observations}

Figure 2 depicts the cross-reef hydrodynamics of the Ouano barrier during a strong wave event recorded between May, 21 and 25, 2016. Note that the interruptions in the Froude and MWL data correspond to the periods where the reef top is dry at low tide. The transport and velocity are inferred from a velocity profiler located at the inner reef boundary, allowing a continuous measurement even at low tide when a cross-reef flux is still present through the canopy (Sous et al., 2019a, b). The typical calm wave functioning is first observed on May, 21. The momentum balance is forced by the wave breaking over the forereef. The gradient of radiation stresses in the breaking zone induces a rise of the free surface, namely the wave-induced setup, such as the MWL level is slightly higher at the reef top (CP3) than in the surf zone (CP2). The related pressure gradient is responsible for the development of an onshore-directed flux across the barrier. The corresponding depthaveraged velocity is about $20 \mathrm{~cm} / \mathrm{s}$. After the reef top, breaking stops and the hydrodynamics shift toward another regime similar to open-channel flows. The dynamics is here mainly controlled by the frictional head loss, where bed shear stress is compensated by a progressive drop of the free surface. This can be observed in Figure 2, bottom plot, where MWL is higher at CP3 than at CP4. This overall behavior, which is modulated by the tidal fluctuations, has been widely described in Sous et al. (2019b).

The offshore wave energy strongly increases during the morning of May, 22. The deep water wave height reaches $4 \mathrm{~m}$, with a peak period around $16 \mathrm{~s}$. The cross-reef transport increases during the rising tide of the morning of May, 22. The depth-averaged reeftop velocity reaches $2.4 \mathrm{~m} / \mathrm{s}$ at high tide, which is one order of 

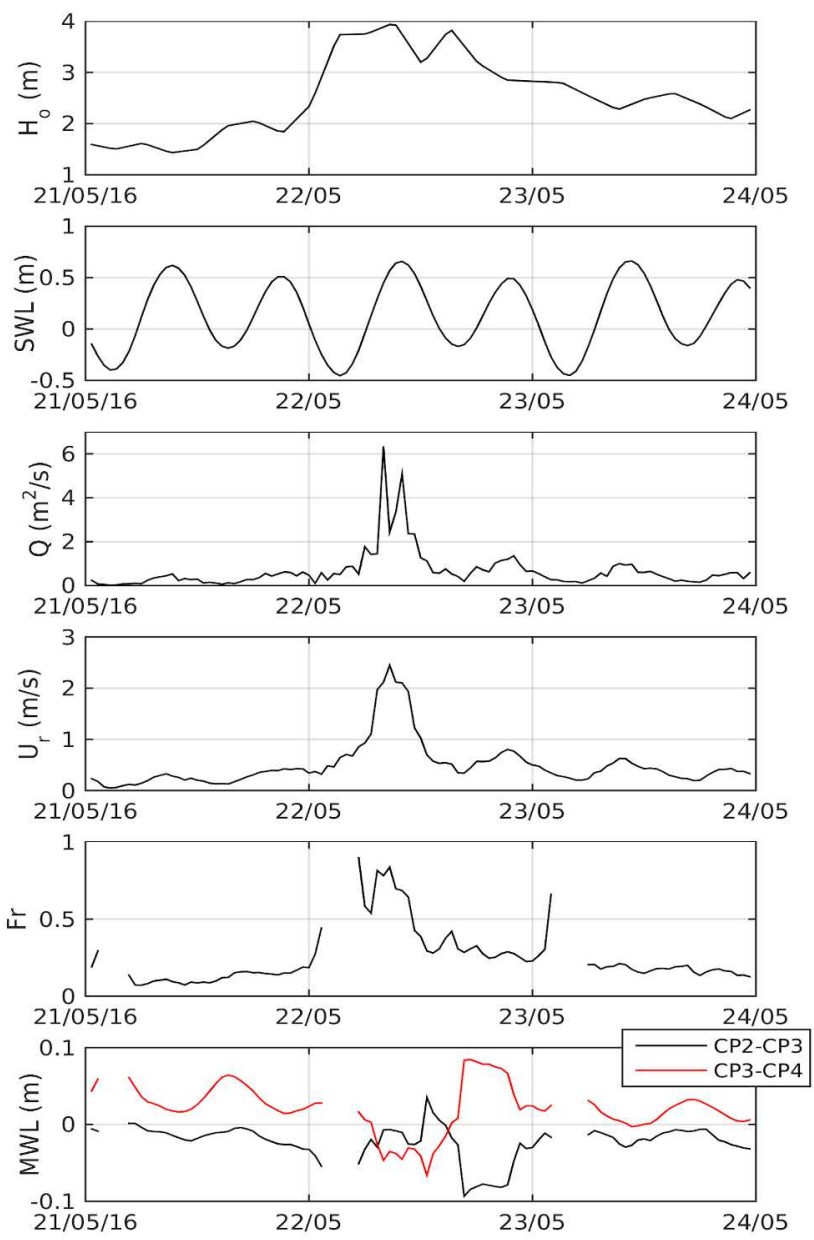

Figure 2. Reef barrier hydrodynamics during the May, 21 to 24, 2016 wave event. From top to bottom: deep water wave height, Still Water Level, Cross-reef transport, Reef-top velocity, Reef-top Froude number and MWL difference between CP2 and CP3 (black line) and CP3 and CP4 (red line). MWL and Fr time series are interrupted when the reef is dry at low tide.

magnitude greater than values typically observed over this reefbarrier (Sous et al., 2017). The Froude number fluctuates between 0.5 and 0.9 during about 6 hours. Such values are close to the theoretical critical value of 1 , but the threshold is not clearly reached. However, it should be recalled that this is a local value estimated over the reef top, where the velocity is inferred from the total transport measurement. Higher values, greater than 1, can therefore be locally reached.

Another important element is the reversal of the mean free surface slope observed between CP3 and CP4 (see Figure 2, bottom plot). In this region, which is located after the reef top, the dynamics is usually governed by head loss due to frictional dissipation. During the extreme magnitude of currents reached during the present wave event, the slope remains positive in a landward oriented referential, i.e. MWL is higher at CP4 than CP3. This is in total contradiction with all existing documentation on this field site (Sous et al., 2019a, b), and leads us to suspect the shifting of the cross-reef flow toward a critical regime.
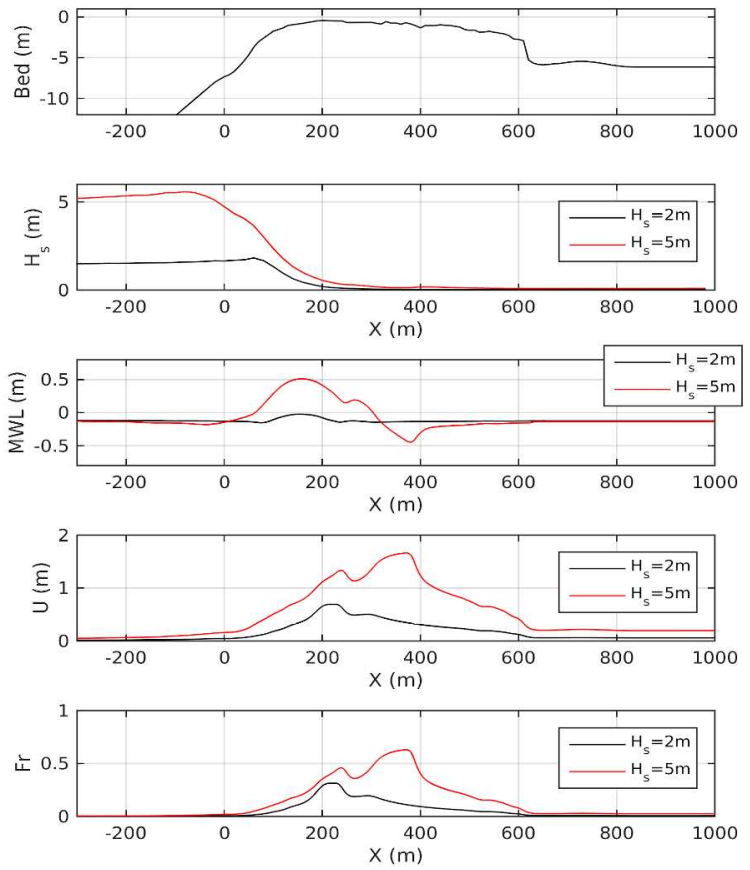

Figure 3. Comparison between two numerical cases performed by the wave-resolving SWASH model: $H_{s}=2 \mathrm{~m}, T_{p}=12 \mathrm{~s}$ and $H_{s}=5 \mathrm{~m}, T=16 \mathrm{~s}$, in black and red lines, respectively. From top to bottom, the 20-min averaged cross-reef distribution of: reef bathymetry, significant wave height, depthaveraged velocity and Froude number.

\section{Numerical Results}

The wave-resolving numerical model is used here to provide a finer description of the spatio-temporal dynamics of the reef barrier in such peculiar conditions.

Figure 3 depicts the cross-shore evolution of time-averaged quantities over the 20-min numerical runs. Two wave cases are compared: $H_{s}=1.5 \mathrm{~m}, T_{p}=12 \mathrm{~s}$ and $H_{s}=5 \mathrm{~m}, T_{p}=16 \mathrm{~s}$, in black and red lines, respectively.

For the moderate wave case, the numerical predictions fairly follow the overall functioning described from the field data with (i) a wave-induced setup in the breaking zone with a maximal value about $0.1 \mathrm{~m}$ around the reef top, (ii) a decrease of the MWL after the reef top due to frictional head loss and (iii) an onshore directed cross-reef current whose magnitude is controlled by the local depth, the total transport being conserved. The increase of wave forcing (red lines in Figure 3) has a strong effect on the reef hydrodynamics. The wave-induced setup reaches around $0.5 \mathrm{~m}$ for the large wave case. The cross-shore profile of MWL shows a more complex evolution, with two inflexion points at $\mathrm{X}=245$ and $348 \mathrm{~m}$ and a clear set-down for the latter position. These changes in slope sign tend to indicate the presence of transition toward critical regimes. However, even if the computation of time-averaged Froude number (Figure 3, bottom plot) shows corresponding local maxima, the critical value $F r=1$ is not reached. The current is also strongly enhanced, with values of about $1.6 \mathrm{~m} / \mathrm{s}$ over the back reef. 


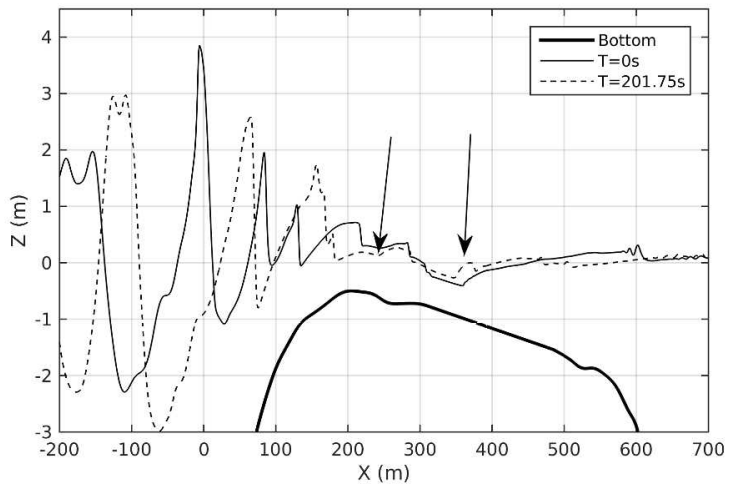

Figure 4. Instantaneous cross-shore profile of free surface elevation at two selected times, in solid and dashed lines, respectively for the offshore significant wave height of $5 \mathrm{~m}$. The black thick line indicates the bottom elevation. The arrows indicate the expected location of hydraulic jumps (corresponding to local maxima in Fr, see bottom panel of Figure 3).

Further insight is gained from the instantaneous profiles of free surface elevation. Figure 4 compares two selected snap-shots of free surface profile. One notes the strong decrease of wave height over the forereef due to wave breaking. In both cases, the presence of a peculiar feature similar to a hydraulic jump is observed on the back reef, around $X=350 \mathrm{~m}$. This feature remains nearly at the same position during the 20 -min run, but its location, amplitude and shape are affected by the incoming wave field, in particular the long infragravity waves propagation. Closer to the reef top, another local deformation of the instantaneous free surface is observed around $\mathrm{X}=250 \mathrm{~m}$. This is an intermittent feature, also governed by the local conditions of current and free surface elevation which are in permanent evolution.

\section{DISCUSSION}

The present field and numerical observations reveal that very strong wave forcing hitting reef barriers are prone to induce a shift toward critical regime, which clearly deviates from the usual hydrodynamical functioning. Such regimes at high Froude numbers are characterized by changes in mean surface slope and formation of hydraulic jumps. They result from the combination of peculiar current and depth conditions which both depend on local wave field, mean current, bottom friction and bathymetry. During very strong wave forcing, the reef barrier is subject to a wide range of wave motions, including short-crested undular bore trains, swell waves, infragravity and very low frequency waves and tides (Sous et al., 2019a) which all affect the depth and current conditions. The shift toward critical regimes and the related development of hydraulic jumps over the barrier is therefore expected to be potentially very variable in time and space. From the present numerical simulations on the Ouano reef barrier performed at a given tidal elevation, one specific position over the backreef appears to be a well-defined location for regime transition. In addition, several intermittent transitions have been observed during the 20-min wave run at various places between the reef top and the backreef, and they all should be strongly affected by the tidal fluctuations.

The development of critical regimes over the reef barrier is expected to have strong consequences on the transport and mixing processes. In a basic state of strong main current observed in large wave conditions, the formation of hydraulic jumps should both reduce depth and strongly enhance turbulent momentum flux. In such conditions, the turbulent mixing and resuspension are expected to drastically increase, inducing extreme events of sediments and nutrients transports, erosion or potentially degradation of living coral colony.

\section{CONCLUSIONS}

The present study aimed to shed light on a nearly unknown process involved over reef barrier systems during strong to extreme wave forcing. The study site is the Ouano barrier reef, New Caledonia. Previous studies have demonstrated that, during usual wave conditions, the bimodal hydrodynamical functioning of the barrier, with a wave-dominated behavior before the reef top and a frictional head loss dominated behavior above the backreef. During extreme wave conditions, the cross-reef current is so strong that transitions toward critical regime can be reached. They are characterized by a complex structure of the mean surface slope, and the development of permanent and/or intermittent hydraulic jumps depending of the local conditions of current and depth, in particular modulated by long wave motions.

\section{ACKNOWLEDGMENTS}

This study was sponsored by the EC2CO OLZO program (CNRS INSU), the OLZO and CROSS-REEF Action Sud (MIO IRD) and the ANR project MORHOC'H (ANR-13-ASTR-0007). The Noumea IRD center and the GLADYS group supported the experimentation. Guillaume Dodet is supported by ESA under the Sea State CCI project. We are grateful to all the contributors involved in this experiment and Dr. Marcel Zijlema (TU Delft) for his help on SWASH.

\section{LITERATURE CITED}

Chevalier, C.; Sous, D.; Devenon, J.L.; Pagano, M.; Rougier, G., and Blanchot, J., 2015. Impact of cross-reef water fluxes on lagoon dynamics: A simple parameterization for coral lagoon circulation model, with application to the Ouano Lagoon, New Caledonia. Ocean Dynamics, 65(11), 1509-1534.

Hench, J.L.; Leichter, J.J., and Monismith, S.G., 2008. Episodic circulation and exchange in a wave-driven coral reef and lagoon system. Limnology and Oceanography, 53(6), 2681.

Lentz, S.J.; Churchill, J.H.; Davis, K.A.; Farrar, J.T.; Pineda, J., and Starczak, V., 2016. The characteristics and dynamics of wavedriven flow across a platform coral reef in the red sea. Journal of Geophysical Research: Oceans, 121(2), 1360-1376.

Lentz, S.J.; Davis, K.A.; Churchill, J.H., and DeCarlo, T.M., 2017. Coral reef drag coefficients-water depth dependence. Journal of Physical Oceanography, 47(5), 1061-1075.

Lowe, R.J.; Falter, J.L.; Bandet, M.D.; Pawlak, G.; Atkinson, M.J.; Monismith, S.G., and Koseff, J.R., 2005. Spectral wave dissipation over a barrier reef. Journal of Geophysical Research: Oceans (1978-2012), 110(C4).

Lowe, R.J.; Falter, J.L.; Monismith, S.G., and Atkinson, M.J., 2009. Wave-driven circulation of a coastal reef-lagoon system. Journal of Physical Oceanography, 39(4), 873-893.

Lowe, R.J.; Leon, A.S.; Symonds, G.; Falter, J.L., and Gruber, R., 2015. The intertidal hydraulics of tide-dominated reef platforms. Journal of Geophysical Research: Oceans, 120(7), 4845-4868. 
Monismith, S.G.; Herdman, L.M.; Ahmerkamp, S., and Hench, J.L., 2013. Wave transformation and wave-driven flow across a steep coral reef. Journal of Physical Oceanography, 43(7), 1356-1379.

Sous, D.; Chevalier, C.; Devenon, J.L.; Blanchot, J., and Pagano, M., 2017. Circulation patterns in a channel reef-lagoon system, Ouano lagoon, New Caledonia. Estuarine, Coastal and Shelf Science, 196, 315-330.
Sous, D.; Dodet, G.; Bouchette, F., and Tissier, M., 2019b. Momentum balance over a barrier reef. Journal of Geophysical Research: Oceans, in Revision.

Sous, D.; Tissier, M.; Rey, V.; Touboul, J.; Bouchette, F.; Devenon, J.L.; Chevalier, C., and Aucan, J., 2019a. Wave transformation over a barrier reef. Continental Shelf Research, 184, 66-80. 